\title{
JOVES INVESTIGADORS I DIFUSIÓ ARQUEOLÒGICA. PRIMER SEMINARI D’ARQUEOLOGIA (UVEG)
}

Passat un any des de la presentació de l'associació, van prenent forma i consolidant-se els objectius que vam establir. Espiera. Compartint Coneixements Arqueològics va nàixer amb la intenció de valorar críticament i difondre l'arqueologia com a ciència entre els diferents tipus de públic. I de conformitat amb aquest ideari, durant aquest primer any hem desenvolupat diverses activitats i projectes. En concret, en aquestes línies, volem recollir el seminari que vam organitzar conjuntament amb el Departament de Prehistòria i Arqueologia de la Universitat de València (UVEG), sota el títol Seminari d'Arqueologia: Noves propostes d'una ciència multidisciplinar (fig. 1).

L'activitat va tindre lloc el dia 24 d'abril de 2012 a la sala Joan Fuster de la Facultat de Geografia i Història de la UVEG. La finalitat principal del seminari era difondre entre la comunitat universitària l'estat actual de les investigacions dutes a terme pels doctorands del departament, com a fil conductor d'un debat més ample que presenta l'arqueologia com a disciplina científica i amb una clara vocació pública.

\section{ARQUEOLOGIA, UNA CIÈNCIA INTERDISCI- PLINAR}

El seminari es va dividir en dues parts, segons la cronologia dels temes a tractar. La primera part, centrada en les investigacions de cronologia prehistòrica, va tindre quatre intervencions. La primera, a càrrec de María Borao, va tractar sobre la tecnologia òssia dels jaciments Paleolítics de la Cova de les Cendres i del Parpalló. L'exposició és va centrar en l'anàlisi de les cadenes operatives de producció dels artefactes en matèries òssies, des de l'aprovisionament de les matèries primeres, la seua manufactura, ús i abandonament, fins que són recuperats per l'arqueòleg al jaciment. Aquest estudi inclou un ampli programa experimental de manufactura i ús dels diferents utensilis mitjançant la realització de repliques sobre os i banya de cérvol. Seguidament, Aleix Eixea va presentar la seua investigació sobre tecnologia lítica i l'ús de l'espai, concretament, en tres jaciments de la façana mediterrània al Paleolític Mitjà: l'Abric de Quebrada, Cova Negra i Cueva Antón. Aquest estudi avaluava globalment les 


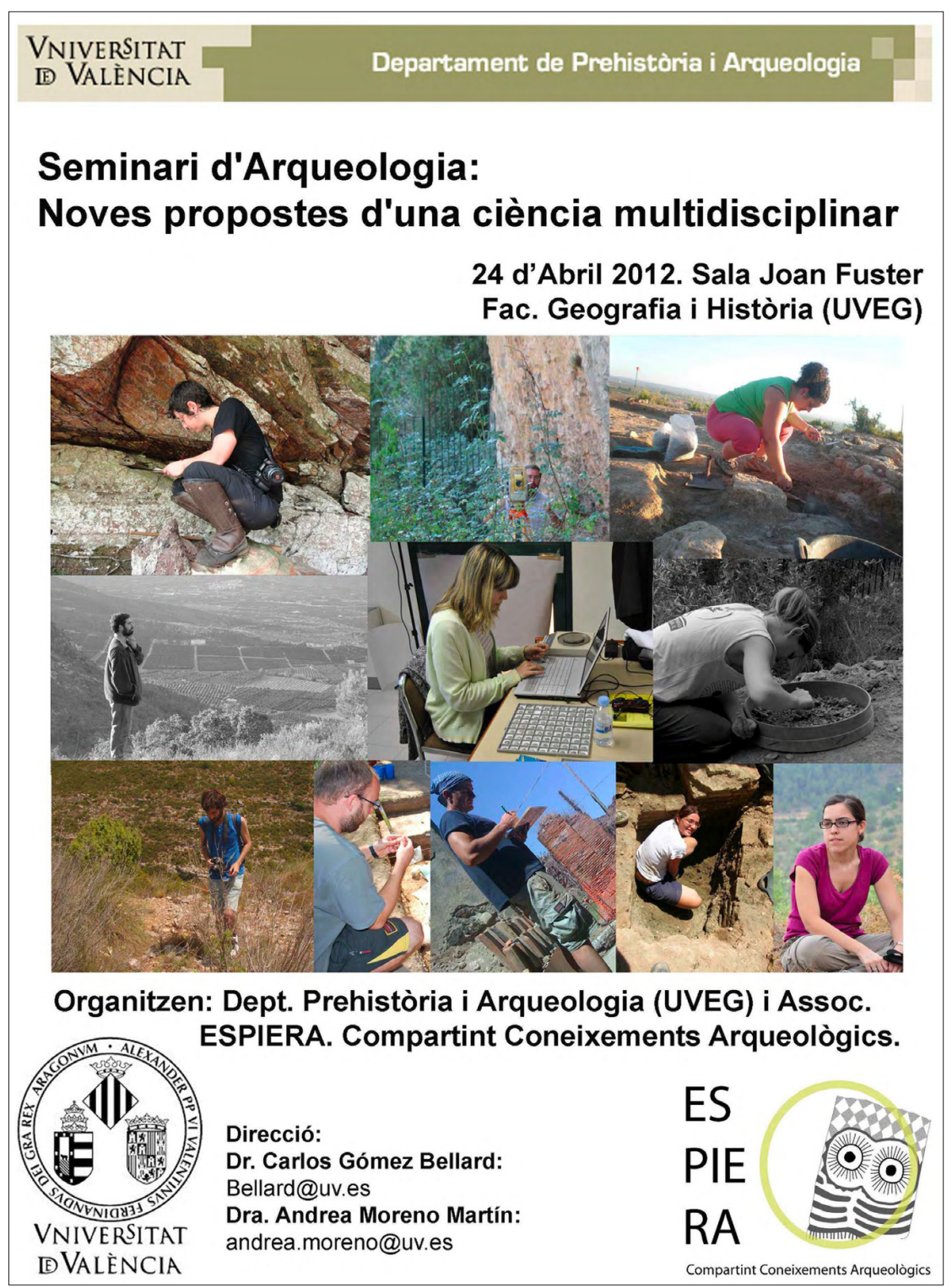

24 d'Abril 2012. Sala Joan Fuster ac. Geografia i Història (UVEG)

Organitzen: Dept. Prehistòria i Arqueologia (UVEG) i Assoc.

IE VALÈNCIA andrea.moreno@uv.es
Fig.1. Cartell de l'activitat. estratègies econòmiques i socials dels grups paleolítics. Les aportacions zooarqueològiques van vindre de la mà de Cristina Real, qui amb el suggeridor títol de ¿Qué cenamos anoche? va fer un complet recordatori de la importància de l'estudi de les restes animals per conéixer cóm vivien les societats passades, a propòsit de l'estudi de la Cova de les Cendres i l'Abric de Quebrada. Aquesta investigació va resultar de gran interès no sols per que podem saber que es menjava al Paleolític, sinó també perquè les restes de fauna ens ajuden a reconstruir el paisatge, els entorns i les estratègies econòmiques.
Per finalitzar la primera part, la Dra. Trini Martínez i el topògraf José Ángel Martínez ens van oferir les últimes novetats metodològiques pel que respecta a l'estudi de l'art rupestre: ús del GPS, Sistemes d'Informació Geogràfica, etc. Amb aquestes tecnologies, i qüestions com l'orientació dels abrics i la seua distribució geogràfica, poden relacionar-se i extraure conclusions que expliquen, per exemple, temes com la finalitat de l'art en relació de les comunitats que el desenvoluparen.

Finalitzat aquest primer bloc de comunicacions, va tindre lloc un debat amb els participants per realitzar les 
primeres reflexions sobre els temes generals exposats. Especialment es féu èmfasi en la cultura material i els espais arqueològics com a punt de partida per a l'anàlisi arqueològica de les societats humanes. Hem de destacar però, que, més enllà de la mera descripció dels objectes, l'arqueologia ofereix propostes teòrico-metodològiques heterogènees que permeten una visió i una reconstrucció holística del passat.

Després d'un breu descans iniciàrem la segona part, en la que van participar sis ponents, que es van centrar en cronologies més recents. La primera intervenció, a càrrec de Salva Pardo, va oferir una introducció sobre les noves propostes d'anàlisi de les xarxes socials a partir de l'ús dels Sistemes d'Informació Geogràfica i simulacions informàtiques basades en agents. El seu estudi, centrat en les dinàmiques socials i econòmiques des del Neolític Antic, fins el Bronze Tardà en el riu Millars (València) i el riu Chico (Almeria), ens permetrà analitzar l'evolució de l'ocupació territorial i les noves formes d'organització social durant la Prehistòria recent. La segona comunicació, presentada per David Quixal, es va centrar en el final de l'època ibèrica i la romanització (ss. II a. C. - II d.C) a la Meseta de Requena. Per a abordar aquest tema, l'autor combina l'estudi clàssic, basat en la geografia, els jaciments i els seus materials, amb una perspectiva territorial del canvi cultural amb la implementació d'anàlisis espacials basats en els Sistemes de Informació Geogràfica.

D'una altra banda, amb l'evocador nom de En un barco de nombre extranjero, Vanessa Albelda ens va parlar d'una de les temàtiques més actuals en el món ibèric: la relació entre els ibers i el comerç marítim. La seua comunicació ens va aproximar a l'estudi actual sobre un dels ports ibèrics més importants de la costa valenciana: el Grau Vell de Sagunt; oferint així una altra modalitat d'estudi arqueològic: la revisió d'intervencions antigues. Seguidament Tono Vizcaíno, amb una interessant exposició basada en exemples de la vida quotidiana, ens va explicar els mètodes que utilitza per a comprendre com són vistos Els ibers des del sofà, és a dir, què pensa i sap la gent quan parla d'ibers. Aquestes propostes són prou novedoses a l'arqueologia peninsular i deixen entreveure la importància de l'Arqueologia com a ciència social i pública.

Per a tancar el seminari, es van tractar temàtiques d'època romana. En primer lloc, Mirella Machancoses ens va mostrar una visió global de l' urbanisme de la Valentia romana. L'autora, partint de les nombroses excavacions d'urgència realitzades en el centre de la ciutat es planteja com abordar i conèixer l'evolució de Valentia, des de la seua destrucció en època sertoriana fins la crisi del s. III d. C. Finalment, Carme Delegido ens va parlar del seu estudi sobre el Tresor de Llíria, format per 5.990 denaris romans. El seu volum fa que estiga considerat entre els tresors imperials més excepcionals de tota Europa. A través d'aquest estudi, es podrà avançar en l'investigació sobre la circulació i la funció política, social i econòmica de la moneda de plata durant l'Alt Imperi (ss. I-III).

Com a punt i final al seminari, vam donar la paraula als participants d'aquesta segona part, per iniciar el debat sobre els temes tractats. Les reflexions finals foren encaminades a remarcar com l'arqueologia és la ferramenta clau per aproximar-nos a les cultures i societats del passat mitjançant l'estudi espacial i temporal dels objectes, els jaciments, els paisatges, etc. El programa tan variat de comunicacions va permetre oferir una imatge enriquidora de l'arqueologia com a disciplina científica i trencar així amb els tòpics que sovint es relacionen amb la nostra professió.

\section{CONCLUSIONS I VALORACIÓ DE L'ACTIVITAT}

Quan l'associació de Espiera es va crear, l'objectiu principal va ser el de compartir els coneixements i els avanços que s'estan produint actualment al món de l'arqueologia. Volíem fer d'Espiera un espai de debat on tots poguérem aprendre de tots, aportant els diferents punts de vista de cadascú, ja que tots estudiem aspectes i períodes diferents dins de l'arqueologia. Doncs bé, aquest esperit de divulgació de coneixements a tots els àmbits socials i científics, de donar a conèixer qui som, què fem i per a què serveix, es plasma en activitats com el seminari que hem fet aquest any i, que esperem, puguem dur a terme anualment en els propers anys.

La idea de fer una activitat com aquesta, va sorgir de 1 ' interès per reprendre una iniciativa oblidada que es realitzava anys enrere per part del Departament de Prehistòria i Arqueologia de la UVEG. Les sessions eren anuals i es feien dins del món universitari, amb la finalitat de donar a conèixer les investigacions que es portaven a terme dins del departament i a banda, donar l'oportunitat als investigadors predoctorals de tindre un escenari de treball on compartir els seus objectius d'investigació, els seus avanços i fins i tot, les seues conclusions. Des 
d'Espiera vam voler reprendre aquesta iniciativa, però intentant ampliar la participació al màxim i arribar a més públics, especialment a les noves generacions d'estudiants. Malauradament amb l'actual sistema d'estudis, el nombre d'assignatures d'arqueologia i prehistòria han sigut dràsticament reduïdes i per això, en Espiera sentim la necessitat i la responsabilitat de compartir i difondre els coneixements arqueològics i de crear aquests espais de diàleg i debat entre tots els públics interessats.

L'assistència al seminari ha sigut tot un èxit, ja que varen vindre vora un centenar de persones: des d'alumnes del grau d'història, del postgrau d'arqueologia, doctorands i professors, fins gent aliena a l'arqueologia. Els debats que es varen produir al finalitzar cada un dels blocs temàtics, van ser molt interessants i enriquidors. A més a més, el seminari ha comprés temàtiques molt variades, fruit de la interdisciplinarietat d'una ciència en constant desenvolupament. El tractament en primer lloc, de temàtiques relatives a la prehistòria, analitzant els diferents camps d'estudi com la tecnologia lítica, òssia, estudis de fauna i d'art, constaten l'alt grau d'especialització. La coordinació dins d'aquestes àrees d'estudi, ens permet apropar-nos, amb els pocs indicis que ens arriben, al coneixement de com aquestes societats primitives vivien i es desenvolupaven en un món molt diferent al nostre. En segon lloc, els treballs de dispersió poblacional a la prehistòria recent, la protohistòria i a l' inici de la història, amb l'intercanvi cultural i comercial dels ibers, l'urbanisme al mon romà i la numismàtica, així com l'estudi de divulgació a la societat, mostren una amplia varietat d'aspectes que també es conjuguen per a donar lloc a la comprensió de com els grups humans han anat evolucionant i de com els contactes entre diferents poblacions han donat origen al nostre món tal i com el coneixem avui en dia.

L'aplicació de les noves tecnologies també ha pres un paper molt important en aquests treballs. L'ús de GPS, diferents programes informàtics de processament d'informació, fotografia, disseny, microscopis, etc., ens donen l'oportunitat d'anar més enllà respecte del que s'havia fet fins ara. Dins de l'associació, la utilització de xarxes socials, com twitter o facebook $^{1}$, ens han servit també per a difondre en directe totes les activitats que hem anant duent a terme aquest any. Un exemple fou el cicle documental que vam realitzar en juny d'aquest mateix any, amb l'objectiu de donar a conèixer un enfocament diferent i poc convencional sobre l'origen de la vida i l' inici de la humanitat.
Esperem poder continuar gaudint d'iniciatives com aquestes i convidem a tots aquells que vullguen rebre informació o participar d'alguna manera en l'associació que es posen en contacte amb nosaltres. Agraïm també al Departament de Prehistòria i Arqueologia, la seua implicació tant en aquesta activitat, com en les constants iniciatives que anem desenvolupant dins de l'associació. També agrair als participants i als directors el seu esforç i temps de dedicació per preparar aquest seminari. I finalment, donar les gràcies al públic per la seua assistència i participació ja que sense ells, aquestes activitats no tindrien cap sentit.

María Borao Álvarez
SonIA Machause LóPEZ
ANDREA MoReno MarTín
Associació ESPIERA. Compartint Coneixements Arqueològics
Departament de Prehistòria i d'Arqueologia
Universitat de València
espiera.arqueologia@gmail.com

\section{NOTA}

1. http://twitter.com/espiera http://www.facebook.com/EspieraCompartintConeixementsArqueologics 